

\title{
A Study on Vulnerability of Urban Neighborhoods to Earthquake (Case Study: Farahzad Neighborhood, Tehran)
}

\begin{abstract}
Iran is considered as one of the most seismic countries in the world and its cities have been frequently damaged by this natural phenomenon. Tehran, as the first metropolis of the country, is no exception to this, and prone to damage also due to its compactness, and being located on three active faults (Mesha fault, North Tehran fault, Rey fault). If activated, Mesha fault, North Tehran fault and Rey fault will destroy $20 \%, 35 \%$ and $55 \%$ of the city, respectively. Farahzad neighborhood in northern Tehran is one of the most seismic parts of Tehran metropolis. Hence, the main objective of this study is to investigate the seismicity of the neighborhood in terms of the risk of earthquakes. For this purpose, descriptive analysis, GIS software and Euclidean distance analysis were used. The results of this study showed that 57 hectares of Farahzad (136 hectares) with a relative area of $41 \%$ are located in a zone with a high earthquake risk (less than $400 \mathrm{~m}$ to the fault line). The area with a high seismic risk ( 400 to 800 meters) covers an area of 39 hectares, 29 percent of the total neighborhood. Also, 20 hectares of total residential buildings (34 hectares), with a relative area of over 58 percent, are located in a zone with a high risk of earthquakes.

Key words: Vulnerability, Earthquake, Crisis, Farahzad.

Copyright $\odot 2017$ Soroush Bazazan Lotfi. This is an open access paper distributed under the Creative Commons Attribution License.

Journal of Civil Engineering and Materials Application is published by Lexis Publisher; Journal p-ISSN xxxx-xxxx; Journal e-ISSN 2588-2880.
\end{abstract}

\section{INTRODUCTION}

$\mathrm{N}$ atural disasters are one of the environmental phenomena that can occur in any part of the planet, depending on the type of environment. These incidents due to their devastating effects always threaten urban settlements. Modern cities in different parts of the world are always at the risk of natural disasters for a variety of reasons, including the lack of suitable location, inappropriate physical development, non-compliance with applicable standards, and the like. One of the dangers that threaten many cities in the world, including our country, is earthquake. In this regard, the United Nations (1992) defines the term "disaster" as "a serious disruption to the functioning of the community and humanitarian or environmental damage beyond the ability of the community." Crisis management is defined as "a process or strategy that is defined for any catastrophic event" (1).
Earthquake is one of the most important natural disasters, an earthquake causes the most severe human and structural vulnerability. Over a decade, around 200 severe earthquakes occur around the world. As the world's population is growing, the vacant areas have rapidly assumed residential uses and, as a result, the magnitude of the phenomenon of earthquake-caused hazards has increased. Iran is considered as one of the most seismic parts of the world and its cities have been damaged frequently due to this natural phenomenon. Tehran, as the first metropolis of the country, is no exception to this, and prone to damage also due to its compactness, and being located on three active faults (Mesha fault, North Tehran fault, Rey fault). If activated, Mesha fault, North Tehran fault, Rey fault will destroy $20 \%, 35 \%$ and $55 \%$ of the city, respectively. Farahzad area in northern Tehran (district 2 of Tehran municipality) is no exception. Due to its 
proximity to young and active faults, the presence of organic texture (Farahzad Village), as well as the steep slopes along Farhazad River and the type of its soil, the region is considered as a potential high threat zone in terms of the earthquake phenomenon. Now the main questions of this research are as follows: what are the vulnerable zones of Farahzad neighborhood givens its physical indices and what strategies can be effective in reducing the negative effect of this phenomenon?

\section{THEORETICAL FRAMEWORK}

\subsection{Natural hazards}

According to the UN International Disaster Reduction Strategic Plan, all risks have two main sources: natural hazards and the risks of technology. In this framework, natural risk is a natural phenomenon that has occurred in the area of human habitation, threatens his life and may lead to disasters. Such hazards are caused by geological, biological, or meteorological causes, or similar processes in human environment (2). To be clearer, any sudden unexpected event that would undermine and eliminate economic, social and physical capabilities, causing, inter alia, financial and financial losses, the destruction of infrastructure and the reduction of employment in the community, is considered as a natural disaster. Natural disasters include earthquakes, floods, droughts, natural pests, volcanoes, forest fires and atmospheric phenomena (3). In developed and leading countries in urban planning, in order to eliminate or reduce long-term effects and consequences of known natural hazards for the life and assets of human societies, plans are developed to prevent natural hazards. The objectives of these projects can be improving existing conditions or protecting future developments. Methods and measures to mitigate the effects of hazards in these plans include structural measures (such as the protection of buildings and infrastructure against the damaging effects of water and wind) or non-structural measures (such as the establishment or improvement of laws and adopting of land-use policies). The development and design of an appropriate risk prevention strategy is based on the following three major processes:

Analysis of the degree of vulnerability;

Development and formulation of a disaster prevention strategy;

Integrating of the plan into the comprehensive plans;

And other designs (4).

\subsection{Risk of earthquakes and cities}

Earthquake means the violent shaking of earth (Dehkhoda's dictionary), which usually causes the rupture of the earth under the pressure. This rupture ranges from a few millimeters to tens of meters, and the energy released from broken stones appears as external waves and sometimes as earthquakes. The earthquake centers, which are formed anywhere from the earth's surface and approximately 700 kilometers below the earth, are the main causes of these disruptions. However, more than 75\% of earthquakes are less than $60 \mathrm{~km}$ deep. The earthquake, as one of the most important natural disadvantages of the earth, has always caused irreparable damage to human settlements in a short period of time. Nowadays, despite the technological advances and increasing human knowledge and ability to control natural disasters, cities still face earthquake and are vulnerable from this perspective. Although it is impossible to prevent the earthquake phenomenon, it is possible to minimize the damage caused through taking due measures (5). Among the natural disasters, the earthquake is one of the most recent challenges facing societies, which not only causes huge economic losses, but also causes many deaths and impedes the sustainable development of communities (6). In other words, the seismic hazard affects more than 35 countries in the world, and each year, it causes deaths more than any other natural hazard. The risk of earthquakes in Iran is well known and the only way to reduce the risks is that of implementing earthquake reduction programs and stabilization of the country against earthquakes (7). The geological structure of the Iranian plateau and its edges are related to the fissured belt system of the third geological period, which is considered as a potential positive factor in terms of minerals and economic resources, while a negative factor in terms of seismic shocks (8).

\subsection{Vulnerability}

According to UNESCO definition: the sensitivity to the occurrence and severity of a natural disaster determines the vulnerability of an environment (9). Vulnerability can be understood as a concept that explains the economic, social, physical, or geographic constraints that reduce the ability of a community to deal with hazards. Considering the different causes of vulnerability, its aspects can be considered to be physical, functional, economic, social and political. Land use planning is a well-organized process that enables the estimating of the risks and vulnerabilities of human settlements. Through the planning process, a program of actions can be set up to create custom changes in the fabric and structure of a city in highly active and changing urban areas, where urbanization occurs at a faster pace, along with economic advances (4). Excessive concentration of activity in cities, and concentration of assets, infrastructure and the sources of production and services have led to the vulnerability of a large number of people. In developing countries, it takes about 12 to 15 years to double the population of these cities, but in the poorer parts of the city, this increase occurs only in 7 years, indicating the vulnerability of the poor in the cities. Poor construction criteria, the use of poor materials and lack of infrastructure in all areas of the cities will exacerbate the vulnerability of the regions. Population pressure, uncontrolled concentration of population in cities and environmental degradation in recent years have led authorities to focus more on potential damages. In this regard, the management of the natural disaster crisis and 
how to achieve a coherent system have always been considered by the country's managers and authorities. The vulnerability of human settlements to natural disasters has steadily increased due to population concentration and economic activity in densely populated areas, disadvantageous and inappropriate condition of the habitat of low-income urban and rural residents. On the other hand, the extent of the damage caused by a disaster is not merely dependent on its destructive power, for example, it is also dependent on the condition of the infrastructural structures hit by the disaster (10). Vulnerability factors are very diverse (natural, physical, social, economic, fundamental, laws and regulations, etc.) and these factors affect each other, not individually, but as a comprehensive system. Even vulnerable groups of crises are also associated with demographic factors such as age, religion, minority, poverty, literacy, etc. (2). There are several factors involved in this, the existence of seismic zones due to the geological situation, the presence of many faults in the center and margins of cities, etc. along with numerous human factors such as urban population, increasing urban housing and poor urban development in terms of earthquake crisis have increased the seismicity of cities (11). Therefore, the vast dimensions of natural disasters and losses in various cities of the world have led to extensive applied research in the field of optimizing the immunization of cities. In urban development plans, reducing the vulnerability of citizens and society to hazard and disaster is necessary. In the meantime, good management can minimize the negative effects of crisis.

\subsection{Crisis and crisis management}

The word crisis is derived from the Greek word Krinein, which means a turning point, especially in the case of illness, and also means the occurrence of a hazard on political-economic issues (3). Crisis Management is one of the important issues that have been given more attention in the fields of theory and practice in recent years. Crisis management operations enable the organization to eliminate some of the crises, effectively manage others, and take the tools necessary for a complete and rapid learning from the occurred crises (12). It can be said that crisis management consists of a set of executive activities and managerial and political decisions depending on different stages and all levels of the crisis to save, reduce losses, prevent life process interruptions, production and services, and maintain communication (10). Crisis management has four main pillars: loss reduction, preparedness, response, reconstruction and normalization. In fact, crisis management is to prepare and provide the necessary measures to deal with the crisis or minimize its destructive effects (13). The views and strategies of crisis management are growing and evolving. In relation to crisis management, four major approaches are now globally defined:

First, a comprehensive approach that requires the development and implementation of strategies to deal with the risks of natural disasters in different fields. Second, the approach to deal with all the risks that are used to improve the status of existing sites and existing buildings. Third, an intra-disciplinary and multidisciplinary approach that is not a comprehensive approach, in which crisis management units are equipped for crisis situations. Fourth, a community approach that actually includes optimizing the organizational status and urban structures, strengthening social capacity through education and information to citizens and organizations involved in crisis management (14).

\section{METHODOLOGY}

The method of this research was developmental and applied based on the purpose, and in terms of research design, this study was an analytical-descriptive research of a survey type. The tool for collecting the required data in this research was field surveys, observation and also documentary methods by referring to written sources including books, papers and reports, and in particular comprehensive and detailed plans.

\section{STUDY'S AREA}

Farahzad area is one of the areas in the second district of the Tehran Municipality, bounded by Alborz Mountains to the south, by Yadgar Imam Highway to the east, by Imamzadeh Davood and Tabarrok Street to the east, and by Farahzad River to the east. Its area is 136 hectares. Farahzad is one of the well-known neighborhoods and is known as "Chaleh Hosseini", which is famous at the end of the 37 and 50 meter left-hand alleys (houses without a plaque of the municipality), and is known with various names, such as the island, the neighborhood of jackals, polygamous men and Europe. The residents, however, prefer these bynames to "Chaleh Hosseini". Real estates in Farahzad are mostly owned by written promise. The majority of the inhabitants lived in the tent for about 2 years and the tents have been ruined by the municipality. And regrettably, people have again and again built houses of clay and straw increasingly, especially along the Farahzad River and the Tabarrok River. Farahzad Residential texture is affected by natural features such as topography, gardens and green space, and the pattern of its physical expansion, except for parts of the southern area, is organic texture with diverse characteristics in terms of climatic orientation. The core of the old Farahzad Village, as well as its downstream gardens, have been affected by various factors such as the separation of gardens and land over time, in other words, large properties and the topographic status of the area have created an organic texture with an indigenous identity. For this reason, this texture can be considered as a fabric of indigenous values. In addition to this ancient center, many marginal textures have been created in recent years, which given the structure of the network and the way parts are separated and partitioned, fall in the category of unplanned textures and settlements, which lacked any physical and cultural 
value and, at the same time, created many problems and

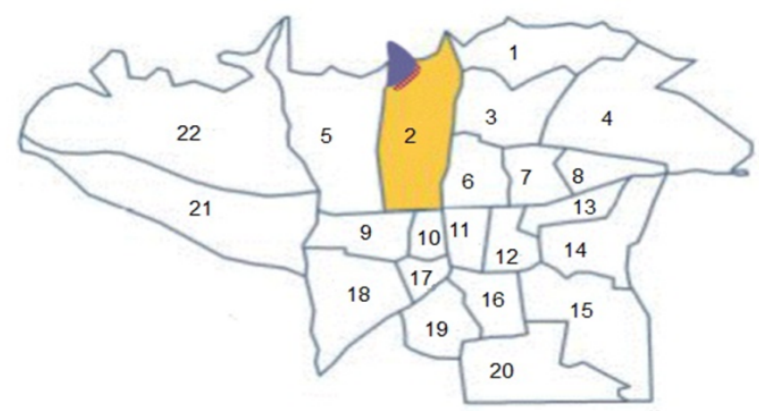

Map 1. Location in Tehran

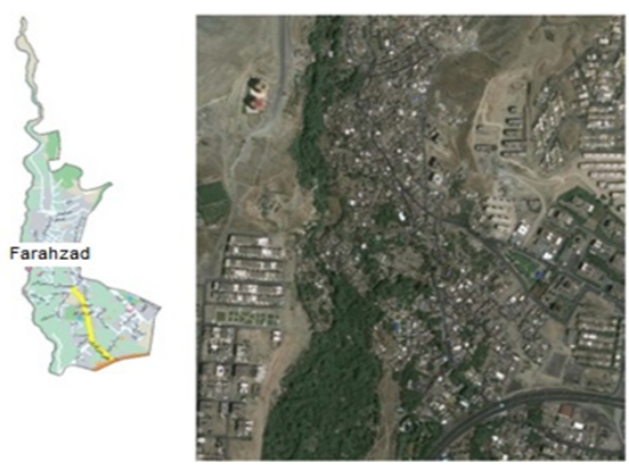

Map 2. Limits of Farahzad Area

\section{ANALYSIS}

\subsection{Compatibility of uses}

The compatibility of each area's use is very important in its vulnerability to risks, as each use interacts with other uses around it. Unless they are compatible with each other, uses can negatively affect each other. In the studies carried out in the study area, given the lack of disturbing uses in the neighborhood and the compatibility of neighborhood uses, the study area was in good condition in terms of the index of compatibility of uses assessment and in terms of vulnerability of zoning, it had no particular problem. In terms of land use, the total area of Farahzad area is 37.41 hectares and the area of the uses of the area is about 21.24 hectares. The largest area related to residential use is about 12.2 hectares, about 57.4 percent of total area of land uses. After residential use, green space is second with $2.11 \%$ (Table 1, Map 3).

Table 1. Percent uses of the area

\begin{tabular}{c|ccc}
\multicolumn{5}{c}{ Table 1. Percent uses of the area } \\
\hline Percent use & Use & Percent use & Use \\
\hline 0.02 & Administrative & 57.44 & Residential \\
11.28 & Green space & 4.95 & Commercial \\
0.16 & Industrial & 0.41 & Educational \\
0.06 & Urban equipment & 0.08 & Higher Education \\
8.95 & Others & 2.39 & Religious \\
7.76 & Mixed & 0.42 & Tourism \\
5.35 & Garden & 0.59 & Healthcare \\
100 & Total & 0.13 & Sanitary \\
\hline
\end{tabular}




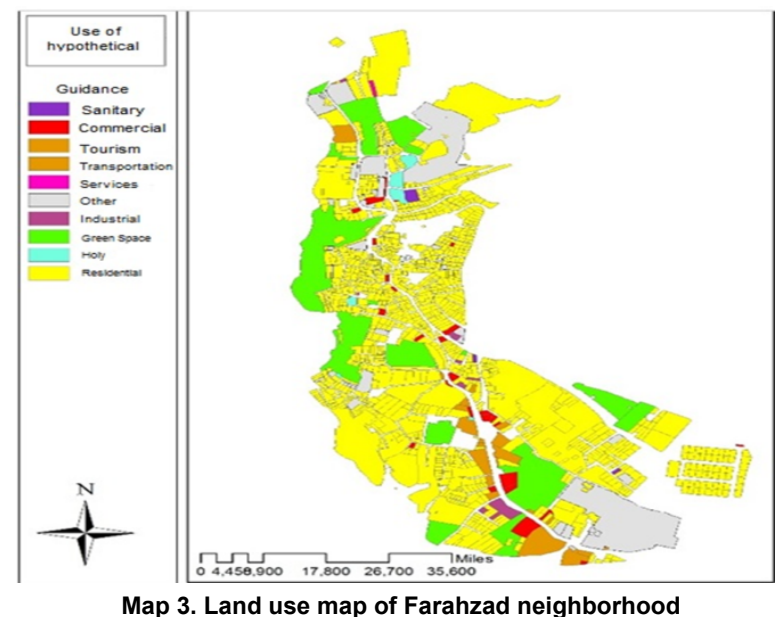

\subsection{Risk of earthquake in Farahzad neighborhood}

According to studies, the total area of the study area is 136 hectares. On the other hand, the risk of faults in the neighborhood of Farahzad is located in the south of the neighborhood. Based on the Euclidean distance analysis, one can calculate the distance of each point of the neighborhood to this fault line and place the earthquake hazard zonation in Farahzad neighborhood. The results of earthquake hazard zonation in the neighborhood indicate that the maximum distance from the fault line is 200 square meters. Map 4 shows earthquake hazard zonation.

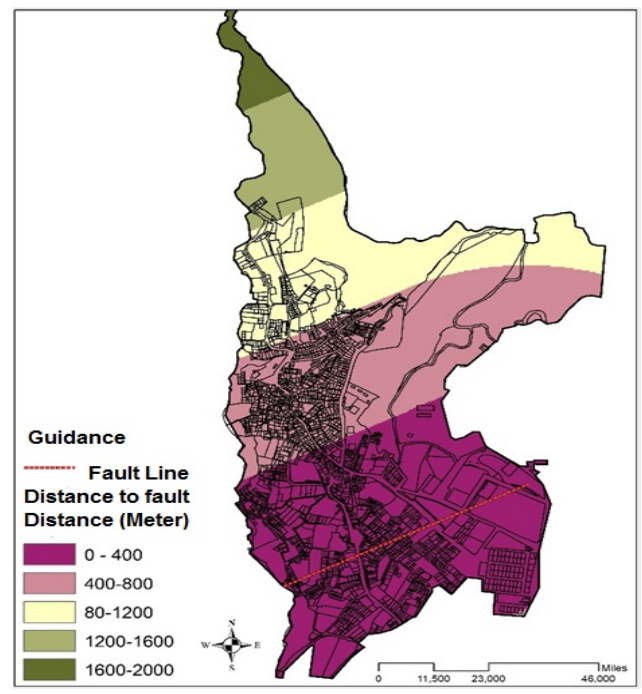

Map 4. Relative seismic hazard zonation map for Farahzad neighborhood

Table 2 shows the area and relative area of each of the earthquake hazard zones. According to this table, 57 hectares of the Farahzad neighborhood with a relative area of 41 percent is located in a zone with a very high risk of earthquake (less than 400 meters to the fault line). The zone with a high seismic hazard (400 to 800 meters) covers an area of over 39 hectares, 29 percent of the total area of the neighborhood. According to studies, 27 hectares, 29 percent of Farahzad neighborhood, are located in a zone with a medium earthquake hazard (800 to 1200 square meters). In the area with a low earthquake hazard (distance of 1200 to 1600 square meters), the area amounts to 9.9 hectares, which is 8 percent of the entire neighborhood. Finally, the area with a very low earthquake hazard (16002000 square meters) covers 3.1 hectares, or 3 percent of the entire neighborhood.

Table 2. Area and relative area of each of the relative areas of the earthquake hazard

\begin{tabular}{cccc}
\hline \multicolumn{2}{c}{ Table 2. Area and relative area of each of the relative areas of the earthquake hazard } \\
\hline Distance to fault line & Relative earthquake risk & Area (hectares) & Relative area (\%) \\
\hline $0-400$ & Very high risk & 57 & 41 \\
$400-800$ & High risk & 39 & 29 \\
$800-1200$ & Medium risk & 27 & 19 \\
$1200-1600$ & Low risk & 9.9 & 8 \\
$1600-2000$ & Very low risk & 3.1 & 3 \\
& & 136 & 100 \\
\hline
\end{tabular}


use in the Farahzad area is 34 hectares. An analysis of the location of these residential uses is shown in Map 5 for each of the relative risk zones of the earthquake.

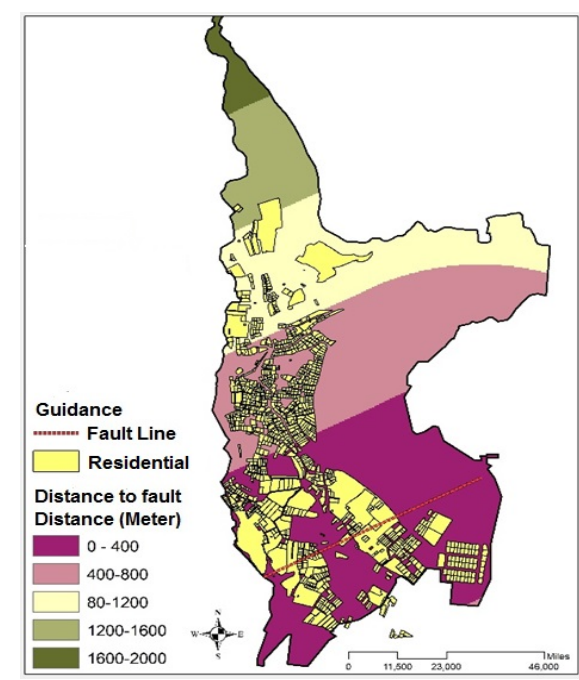

Map 5. Location of residential uses relative to each of the earthquake hazard zones

According to Table 3, 20 hectares of total residential use with a relative area of over 58 percent are located in a zone with a very high risk of earthquakes. 7.5 hectares equaling $22 \%$ of the total residential use are in a high-risk area of the earthquake. Also, 6 hectares, 18 percent of the total residential uses, are in the medium-risk zone, and finally a half-hectare, 2 percent, is in the low risk zone of the earthquake.

Table 3. Area and relative area of residential use relative to earthquake hazard zonation

\begin{tabular}{|c|c|c|c|}
\hline Distance to fault line & Relative earthquake risk & Area (hectares) & Relative area (\%) \\
\hline $0-400$ & Very high risk & 20 & 58 \\
\hline $400-800$ & High risk & 7.5 & 22 \\
\hline $800-1200$ & Medium risk & 6 & 18 \\
\hline $1200-1600$ & Low risk & 0.5 & 2 \\
\hline $1600-2000$ & Very low risk & 0 & 0 \\
\hline \multicolumn{2}{|c|}{ Total } & 34 & 100 \\
\hline
\end{tabular}

\section{CONCLUSION}

In this research, the vulnerability and earthquake risk in Farahzad Historical neighborhood was investigated. The results indicate that a large part of the neighborhood, 70 percent of the neighborhood, is under high risk and very high risk of earthquakes. This has raised the possibility of an earthquake occurring in this neighborhood. In this regard, strategies are described as follows:

1- Emphasis on the development of a comprehensive crisis management model; the main reason for this emphasis is that although a number of precautionary measures to cope with natural disasters have been taken, past experiences have shown the fact that more comprehensive measures should be taken for both before and after the crisis and these actions should be supported by a strategic plan that is tailored to the regional specific risk maps.

2. Resolution of the probable problems in the crisis management process regarding disaster preparedness and ensuring coordination between organizations after the natural disaster.

3. In order to manage the natural disasters in an efficient manner, planning should be done by taking into account the areas and precautions necessary to meet the specific needs of these areas.

4- Holding training classes for people to raise the level of readiness, awareness and cooperation to protect themselves during the earthquake.

5- Economic empowerment of people to rehabilitate residential buildings against earthquakes,

6. More control over housing construction

7- Designation of temporary settlement places.

\section{FUNDING/SUPPORT}

Not mentioned any Funding/Support by authors.

\section{ACKNOWLEDGMENT}

Not mentioned any acknowledgment by authors.

\section{AUTHORS CONTRIBUTION}

This work was carried out in collaboration among all authors.

\section{CONFLICT OF INTEREST}

The author (s) declared no potential conflicts of interests with respect to the authorship and/or publication of this paper.

\section{REFERENCES}

1. Caymaz E, Akyon FV, Erenel F. An exploratory research on strategic planning in public institutions: Turkish prime ministry disaster and emergency management presidency case. Procedia-Social and Behavioral Sciences. 2013;99:189-95. [Crossref]

2. Birkmann J, Cardona OD, Carreño $M L$, Barbat $A H$, Pelling $M$, Schneiderbauer $\mathrm{S}$, et al. Framing vulnerability, risk and societal responses: 
the MOVE framework. Natural hazards. 2013:67(2):193-211. [Scopus] [Crossref]

3. Rezaei M, Hosseini S, Hakimi H. Strategical planning for crisis management in Yazd's historical tissue by using SWOT. 2012.

4. Hosseini KA, Hosseini M, Jafari MK, Hosseinioon S. Recognition of vulnerable urban fabrics in earthquake zones: a case study of the Tehran metropolitan area. Journal of Seismology and earthquake Engineering 2009;10(4):175

5. Nateghi-A F. Earthquake scenario for the mega-city of Tehran. Disaster Prevention and Management. 2001:10(2):95. [Crossref]

6. $\mathrm{Li} \mathrm{H}, \mathrm{Yi} \mathrm{T}, \mathrm{Gu} \mathrm{M}$, Huo L. Evaluation of earthquake-induced structura damages by wavelet transform. Progress in Natural Science. 2009;19(4):461 70. [Scopus] [Crossref]

7. Gashti HP, Shahrodi K. An Overview on Locating of Chain Stores Construction by using of Analytic Network Process in Geographic Information System Environment.

8. Negaresh H. EARTHQUAKES, CITIES, AND FAULTS. 2005.
9. Thywissen K. Core terminology of disaster reduction. Measuring vulnerability to natural hazards: Towards disaster resilient societies, United Nations University Press, Hong Kong. 2006. [PubMed]

10. Atash $\mathrm{F}$. The deterioration of urban environments in developing countries: Mitigating the air pollution crisis in Tehran, Iran. Cities. 2007;24(6):399-409. [Scopus] [Crossref]

11. Pourmohammadi M, MOSAYEBZADEH A. the vulnerability of iranian cities against earthquake and the role of neighborhood participation in providing assistance for them. 2008.

12. HOSSEINI SY, DAMNABI AA. the impact of strategic management on the quality of crisis management case study: railway transportation industry

13. MacEachren AM, Robinson AC, Jaiswal A, Pezanowski S, Savelyev A Blanford J, et al., editors. Geo-twitter analytics: Applications in crisis management. 25th International Cartographic Conference; 2011.

14. Hayles CS. An examination of decision making in post disaster housing reconstruction. International Journal of Disaster Resilience in the Built Environment. 2010;1(1):103-22. [Scopus] [Crossref] 


\section{Lexis Press ${ }^{\circledR}$}

\section{Paper Title:}

A Study on Vulnerability of Urban Neighborhoods to Earthquake (Case Study: Farahzad Neighborhood, Tehran)

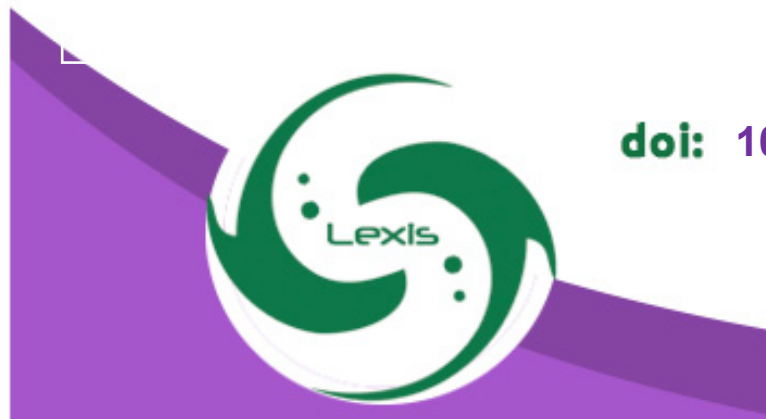

Also You can directly access to other formats of this paper:

\section{G. ब迎? $\mathrm{R}_{\mathrm{M}} \mathrm{BIBT}_{\mathrm{E}} \mathrm{X}$}

Lexis Publishing Corporation provided below advanced features for this paper:

- Special QR id

- Endnote references writing

OPEN ACCESS

- Special doi number from CrossRef

- Fully content checked by Lexis antiplagiarism software

- Open Access

- Professional Read online

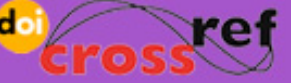

- High visibility and professional indexing formats

- Bookmarks enabled

- Language improved

- Structure improved

\section{Paper Type:}

Research (Original) 